\title{
An Economic Analysis of Oil Sands Mining Options*
}

\author{
R. S. Suglo
}

Suglo, R. S., (2009), “An Economic Analysis of Oil Sands Mining Options”, Ghana Mining Journal, Vol. 11, pp. $53-60$.

\begin{abstract}
Mining projects normally involve huge levels of capital outlay with their attendant high investment risks. Thus, all new mining projects and existing projects have to be economically evaluated to assess their viabilities and whether they add value to the company's portfolio. Economic analysis is one of the best tools for evaluating and comparing different projects or investments options. Various economic evaluation criteria such as the Net Present Value, Profitability Index, Internal Rate of Return and Discounted Payback Period are commonly used, alone or in combination, to determine the acceptability or attractiveness of projects and to aid in the selection of the best investment ventures from a number of options.

In this paper, economic, risk and sensitivity analyses were conducted on two oil sands mining options at Syncrude Mine in Canada. These are the Current Mining System (CMS) and the Cyclic Excavator Conveyor Belt Control System (CycEx CBCS). The results of detailed economic analysis show that the net present value (NPV) of the CMS option is $\$ 3.20^{\prime} 10^{10}$ while that for the CycEx CBCS option is $\$ 4.06^{\prime} 10^{10}$. The profitability indices for the CMS and CycEx CBCS options are 19.37 and 43.37 respectively. The internal rates of return of the CMS and CycEx CBCS options were calculated to be 29.02\% and 33.37\% respectively. Both the CMS and CycEx CBCS options have very short discounted payback periods ( $\leq$ 0.27 years). The results of risk characterisation of the two mining options show that there is $85 \%$ probability that the NPVs of the CMS and CycEx CBCS options will be greater than $\$ 2.69^{\prime} 10^{10}$ and $\$ 3.42^{\prime} 10^{10}$ respectively. The results of sensitivity analysis show that the input variables that significantly affect the NPV in both mining options are the discount rate, production rate, oil price, exchange rate, and the federal and provincial tax rates. In general, changes in input parameters such as discount rate, scheduled mine production capacity and time, price of oil per barrel and total operating costs had lower effects on the NPV of the CycEx CBCS option than the CMS option. The calculated economic parameters together with the results of the risk and sensitivity analyses show that the CycEx CBCS option is more economically viable than the CMS option.
\end{abstract}

\section{Introduction}

Materials handling in surface mining operations involve discrete and continuous flow units and processes. Discrete materials loading and transportation systems (e.g. the shovel-truck system) are predominantly used in open pit mines because they have high equipment mobility, allow high flexibility in planning and scheduling of operations, and easily cope with the frequent changes in the pit configuration. As most open pits become wider and deeper, haul roads lengthen leading to dramatic increases in the haulage costs and cycle times, lower production rates and system efficiencies. The production cost of oil sands is generally over 11 times that for conventional crude oil. It is therefore necessary to reduce the unit operating costs in oil sands mining to make it competitive on the energy market. The effort to reduce production cost has focused on several fronts including new mining methods and advanced production technologies. Research and industry initiatives have focused on new production technologies to reduce truck haulage costs because these constitute a significant portion of the production cost (»26\%), and together with shovels, they comprise $40 \%$ of the total cost (Bishop, 1968; Michaelson, 1979;
Sullivan, 1990; Anon., 1993). Thus, most mine operators are searching for cheaper mining and haulage systems that will ensure the optimum profitabilities of their operations. Bulk materials transport systems such as belt conveyors and hydraulic transport systems have been noted to offer lower operating costs (Anon., 1979; Michaelson, 1979; Frizzell and Martin, 1992). They are also versatile and have practically unlimited range of capacities and are increasingly being employed in the bulk transportation of materials in large surface mines. They offer competitive advantages over other materials handling systems (e.g. truck haulage) in reducing the unit production costs of the materials.

The current haulage system in the oil sands mines uses trucks to haul oil sands materials to a slurrification unit from where the slurry is pumped to the treatment plant through rigid pipelines in the Hydrotransport System (HTS). The low production cost of bulk transport systems has generated interest in linking the shovel at the face with the fixed hydrotransport system by a train of flexible pipelines or belt conveyor wagons. The materials excavated by the shovel will be dumped into a hopper, crushed and slurried at the face before being pumped through either rigid or flexible pipelines to

\footnotetext{
* Manuscript received July 30, 2008

Revised version accepted November 3, 2009
} 
join the fixed hydrotransport system. This new technology is termed the "At Face Slurrying" (AFS) method. The AFS technology is designed to optimize the efficiencies and costs of hydraulic and belt conveyor transport systems by extending the hydraulic transport or conveyor belt systems to production faces.

The shovel-truck system, which is referred to as the Current Mining System (CMS) in this paper, is widely used in most surface mines throughout the world. Due to the operating flexibility, mobility and resale value, truck haulage is the favoured method for moving both ore and waste in open pit mines (Frizzell and Martin, 1992). The shoveltruck system is currently being used in mining and waste stripping operations in most hard rock and oil sands mining companies like Syncrude Canada Ltd. and Suncor Energy Inc., both in the province of Alberta, Canada. The CMS comprises shovels as the primary loaders with diesel-powered dump trucks that are dispatched or allocated to each excavator. The loaded trucks transport the materials to dump sites at the crusher-slurrification facility or to the waste dump site. The system comprises discrete loading and haulage units whose hourly outputs are characterized by their cycle times.

The Cyclic Excavator Conveyor Belt Control System (CycEx CBCS) comprises a shovel, a crawlermounted mobile crusher, a train of belt conveyor wagons, a mixing tower and a slurrification facility. The shovel loads its materials into the crawlermounted hopper located at the face. Apron feeders transfer the materials to sizers then into double roll crushers for reduction in size. The crushed materials are sized and conveyed on a train of crawlermounted belt conveyor wagons to a slurrification facility. In the slurrification facility the materials are conditioned into slurry for transport through the main HTS to the main processing plant (Changirwa et al., 2000). The slurrification unit also receives materials from other faces in a multibench, multi-face mining and materials flow system. This is to ensure that there is continuous flow of materials from the cyclical shovels to the slurrification unit. The aim is to meet the required production targets, and avoid downtimes of the slurrification unit because of a problem at any mining face. Thus the novel at face slurrying system (AFS) is intended to take advantage of the lower unit operating costs, higher payload-deadweight ratio (Kutschera, 1994), and higher efficiencies of belt conveyor and hydraulic transport systems by extending the belt conveyor and hydraulic transport systems to the production faces in the pits.

Different combinations of equipment can be used in a mine to achieve the desired production targets. However, some equipment combinations and their operating times result in lower unit operating costs and higher system efficiencies than others. In a typical open pit mine, both the waste and ore must be mined at the required rates simultaneously. The waste stripping operation has to precede the ore mining and must continue at a good rate to ensure that sufficient ore material is exposed to meet the required ore production targets. The thickness of the deposit averages $60 \mathrm{~m}$ in Syncrude Mine while the daily production target is 262000 tonnes at an average stripping ratio of 1.1 . Thus for every tonne of ore mined about 1.1 tonnes of waste have to be removed to maintain the stripping ratio. This means that the amount of ore to be mined is almost the same as that of the waste stripping requirements. In this paper economic, risk and sensitivity analyses are conducted on the CSM and on the CycEx CBCS in oil sands mining to find out how changes in the discount rate, operating cost, oil price and, federal and provincial taxes affect the NPV and to determine the more viable mining option.

\section{Economic Analysis of Mining Options}

Mining projects normally involve huge levels of capital outlay with their attendant high investment risks. Accordingly, all new mining projects and existing projects have to be economically evaluated to assess their viabilities and whether they add value to the company's portfolio. Economic analysis is one of the best tools for evaluating and comparing different projects or investments options. Various economic evaluation criteria are commonly used, alone or in combination, to determine the acceptability or attractiveness of projects and to aid in the selection of the best investment ventures from a number of options (O’Neil, 1998). Some of the economic evaluation criteria used in this work are the Net Present Value (NPV), Profitability Index (PI), Internal Rate of Return (IRR) and Discounted Payback Period (DPBP). Even though the unit cost of production of the two options may be used to determine the better option, it is much better to assess both options using the aforementioned economic evaluation criteria to give a global picture of the two mining options. Due to the unpredictable nature of mineral prices and other economic indices on the world market as well as the frequent changes in political regimes in some states and provinces, a comprehensive economic, risk and sensitivity analyses are required to determine the effects of changes in discount rate, oil prices, unit operating costs and, provincial and federal taxes on the viability of the two mining options.

Table 1 summarizes some of the sample input data used in the economic analysis of the CMS and CycEx CBCS options. In Syncrude Mine, about one barrel of oil is obtained for every two tonnes 
Table 1 Input Data for Economic Analysis

\begin{tabular}{|l|c|c|}
\hline Item & CMS Option & CycEx CBCS Option \\
\hline Daily Production (tonnes/day) & 262000 & 262000 \\
\hline No. of Working days/yr & 365 & 365 \\
\hline Price/barrel (US\$) & $29.80 \pm 2.67$ & $29.80 \pm 2.67$ \\
\hline Cost per 320-tonne truck & $\$ 2600000.00$ & - \\
\hline Cost per 360-tonne truck & $\$ 3000000.00$ & - \\
\hline Shovel (O\&K RH200) & $\$ 10000000.00$ & $\$ 10000000.00$ \\
\hline Crusher (mobile) & $\$ 22000000.00$ & 13000000.00 \\
\hline Belt conveyor wagons (in 20 m lengths) & - & 2500000.00 \\
\hline Mobile transfer conveyor & - & 9800000.00 \\
\hline Federal tax rate (\%) & $15 \pm 5.3$ & $30 \pm 8.2$ \\
\hline Provincial tax rate (\%) & $30 \pm 8.2$ & $6.2 \pm 1.4$ \\
\hline Interest rate (\%) & $6.2 \pm 1.4$ & 5.00 \\
\hline Royalties (\%) & 5.00 & $1.486 \pm 1.325$ \\
\hline Currency exchange rate & $1.486 \pm 1.325$ & 15 \\
\hline Discount rate (\%) & 15 & $2.82 \pm 1.26$ \\
\hline Inflation rate (\%) & $2.82 \pm 1.26$ & \\
\hline
\end{tabular}

of ore mined. Testing of the data collected from the time and motion studies using the stabilised probability plot method and BestFit software show that the data closely fit various statistical distributions (Suglo and Szymanski, 1995; Anon., 1997, Suglo, 2004, Suglo et al., 2009). The various costs used in the calculations were assumed to vary by $\pm 25 \%$ of their mean values.

The Double Declining Balance (DDB) method of depreciation is used in the mine. The depletion allowance is taken as the minimum of $5 \%$ of gross revenue or $10 \%$ of Pre-Capital Cost Allowance (PreCCA) while the average exchange rate of the US dollar to the Canadian dollar is assumed to be 1.486. An allowance of $25 \%$ of the cost is given for contingencies. Detailed economic analysis was done on the CMS and CycEx CBCS options using information supplied by the mine authorities, quotations from equipment manufacturers, federal and provincial sources, and Bank of Canada webpages (Anon., 2003a; Anon., 2003b; Coward, 2003). Table 2 summarises the results of the economic analysis conducted on the two mining options. The results show that both mining options are viable with high net present values $\left({ }^{3} \$ 3.20^{\prime} 10^{10}\right)$, profit- ability indices ( $>19 \%)$ and internal rates of return (> 29.02\%) and extremely short discounted payback periods $(\leq 0.27 \mathrm{yr})$.

From Table 2, the CycEx CBCS option is more economically viable than the CMS option. Its NPV is 1.27 times that of the CMS option. The PI and IRR of the CycEx CBCS option are 2.24 and 1.13 times that of the CMS option respectively. The CycEx CBCS option also has almost half the DPBP of the CMS option. Against a discount rate of $15 \%$ set by the company, the CycEx CBCS option is clearly the better option to invest in. Detailed economic calculations show that when six shovels are employed in combination with twenty four 360-tonne trucks in the CMS option the operating cost is $\$ 1.386$ per tonne (\$2.774/barrel). With the CycEx CBCS option, when six shovels are employed in combination with 18 belt conveyor wagons (each $20 \mathrm{~m}$ in length), two mobile transfer conveyors and a slurrification facility, the operating cost is $\$ 0.779 /$ tonne ( $\$ 1.558 /$ barrel). Thus the unit operating cost of the CMS option is about 1.78 times that of the CycEx CBCS option. 
Table 2 Summary of Economic Analysis of Mining Options

\begin{tabular}{|c|c|c|c|}
\hline \multirow{2}{*}{$\begin{array}{l}\text { Economic } \\
\text { Parameter }\end{array}$} & \multicolumn{2}{|c|}{ Mining Option } & \multirow{2}{*}{$\begin{array}{c}\text { Ratio } \\
\text { (CBCS/CMS }\end{array}$} \\
\hline & CMS & CусЕх CBCS & \\
\hline $\begin{array}{l}\text { Net Present Value } \\
(\mathrm{NPV}, \$)\end{array}$ & $3.20 \times 10^{10}$ & $4.06 \times 10^{10}$ & 1.27 \\
\hline $\begin{array}{l}\text { Profitability Index (PI) } \\
\text { (unitless) }\end{array}$ & 19.37 & 43.37 & 2.24 \\
\hline $\begin{array}{l}\text { Internal Rate of Return } \\
\text { (IRR, \%) }\end{array}$ & 29.02 & 33.37 & 1.15 \\
\hline \begin{tabular}{|l|} 
Discounted Payback \\
Period (DPBP, yr) \\
\end{tabular} & 0.27 & 0.16 & 0.59 \\
\hline
\end{tabular}

\section{Risk Characterisation and Sensitivity Analysis}

Every mining investment venture faces many risks in terms of the huge levels of capital outlay required, the timing of cash inflows and outflows. Other factors that increase the risk include frequent and unpredictable changes in the market prices of commodities and equipment, type of legislations on taxes, laws on environmental protection, the prevailing political environment within the country in which the project is located, and the general consciousness of the people. Risk analysis is required to quantify the level of uncertainty in the venture and to assess the likelihood of the venture achieving certain targets under varying economic and technical conditions. What-if analyses have to be conducted to determine how, for example, the NPV is affected by changes in the oil price, discount rate, unit operating cost and level of provincial and federal taxes. The Toprank module of the @Risk software was used to conduct the risk characterisation and sensitivity analyses of the CMS and the CycEx CBCS options.

\subsection{Risk Charaterization of Mining Options}

Figs. 1 and 2 show the risk characterisation of NPV and the probability of success of the two mining options. Fig. 1 shows that for the CMS option, the mean NPV is $\$ 3.20^{\prime} 10^{10}$ with a standard deviation of $\$ 4.92^{\prime} 10^{9}$. The minimum and maximum values of the NPV are $\$ 1.19^{\prime} 10^{10}$ and $\$ 5.19^{\prime} 10^{10}$ respectively. For the CycEx CBCS option, the mean, standard deviation, minimum and maximum values of the NPV are $\$ 4.06^{\prime} 10^{10}$, $\$ 6.25^{\prime} 10^{9}, \$ 1.71^{\prime} 10^{10}, \$ 6.38^{\prime} 10^{10}$ respectively. Thus the NPV of the CycEx CBCS option has a larger variance than that of the CMS option. From Fig. 2, there is a $15 \%$ probability that the NPV of the CMS and CycEx CBCS options will be $£ \$ 2.69$ ' $10^{10}$ and $£ \$ 3.42 ' 10^{10}$ respectively. The graph also shows that the values of the NPV at the $5^{\text {th }}$ and $95^{\text {th }}$ percentiles are $\$ 2.39$ ' $10^{10}$ and $\$ 4.01$ ' $10^{10}$ respectively for the CMS option. For the

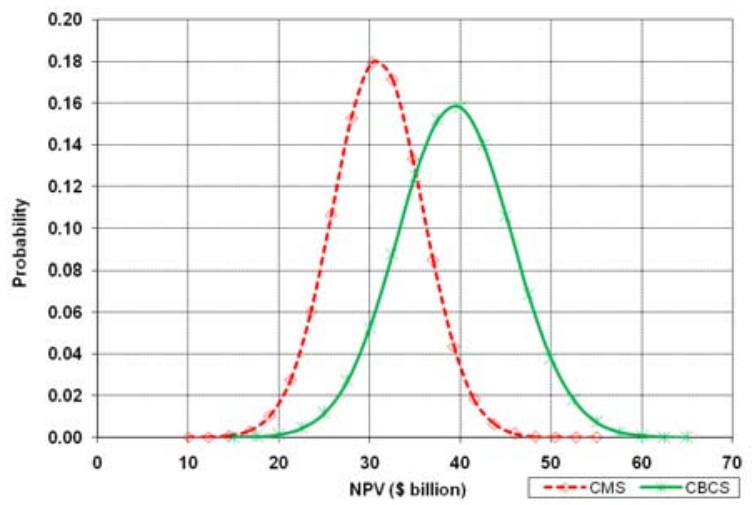

Fig. 1 Risk Characterisation of NPV of Mining Options (Source: Suglo et al., 2009)

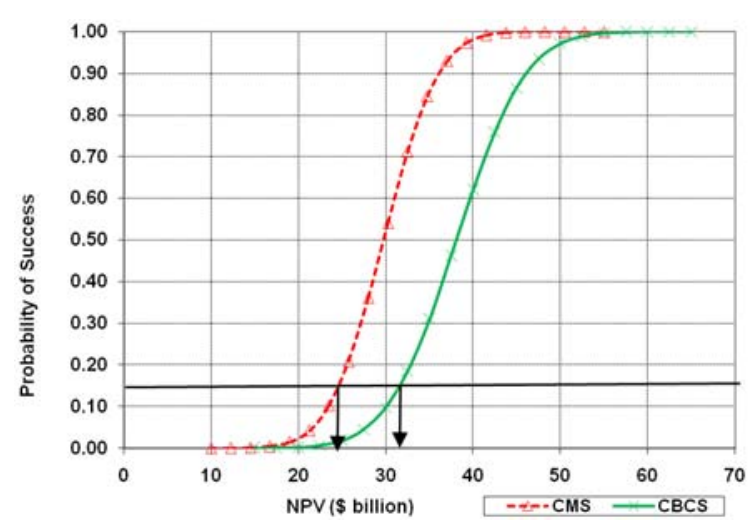

Fig. 2 Probability of Success of Mining Options (Source: Suglo et al., 2009)

CycEx CBCS option the NPV values are \$3.03 ' $10^{10}$ and $\$ 5.09^{\prime} 10^{10}$ at the $5^{\text {th }}$ and $95^{\text {th }}$ percentiles respectively.

\subsubsection{Risk Characterisation with Varying Oil Prices}

Figs. 3 and 4 are the risk characterisation of the NPV of the mine at varying oil prices using the CMS and CycEx CBCS options respectively. Fig. 3 shows that at an oil price of US\$15, the variance in the NPV is much smaller than those at higher oil prices. As expected, both Figs. 3 and 4 show that as the oil price increases, the NPV also increases (i.e. oil price has a positive impact on the NPV).

\subsubsection{Risk Characterisation with Varying Oper- ating Costs}

Fig. 5 shows the variation of the NPV with operating cost of the CMS and CycEx CBCS options. The gradients of the curves show that the NPV of the CMS option is affected more by changes in the operating cost than the CycEx CBCS option. Fig. 5 also shows that the NPV of the CMS option is zero 


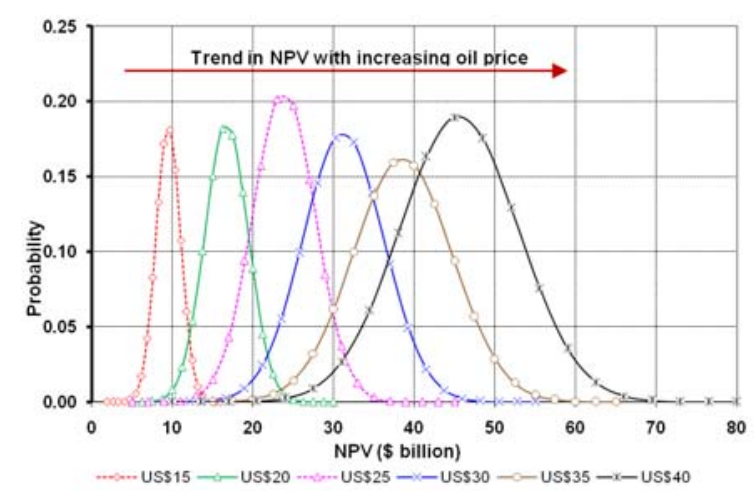

Fig. 3 Risk Characterisation of NPV at varying Oil Prices (CMS Option) (Source: Suglo et al., 2009)

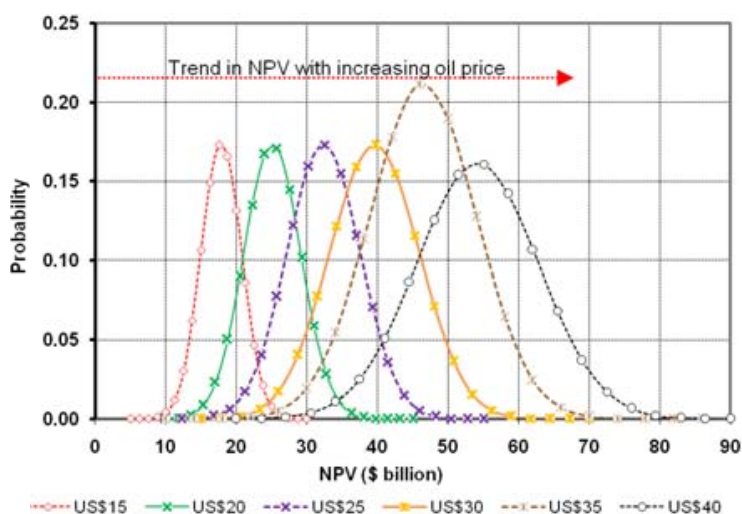

Fig. 4 Risk Characterisation of NPV at varying Oil Prices (CycEx CBCS Option) [Source: Suglo et al., 2009]

at an operating cost of $\$ 10.62 /$ barrel while that of the CycEx CBCS option is $\$ 21.68 /$ barrel. Thus the CycEx CBCS option has a wider range of operat

ing cost than the CMS option and thus a lower probability of failure. This indicates that at operating costs above $\$ 10 /$ barrel, the probability of failure of the CMS option is very high. For the CycEx CBCS option, the chances of failure are high when the operating costs exceed \$20/barrel. Thus it would be safer to maintain the unit operating costs in the CMS and CycEx CBCS options below \$10/barrel and \$20/barrel respectively.

\subsubsection{Risk Characterisation with Varying Tax Rates}

Fig. 6 shows the relationship between NPV and taxes (sum of provincial and federal taxes). It shows that the level of provincial and federal taxes has a negative impact on the NPV of the mine in both mining options. The slightly higher gradient of the CycEx CBCS option indicates that it is affected more by the level of taxes than the CMS

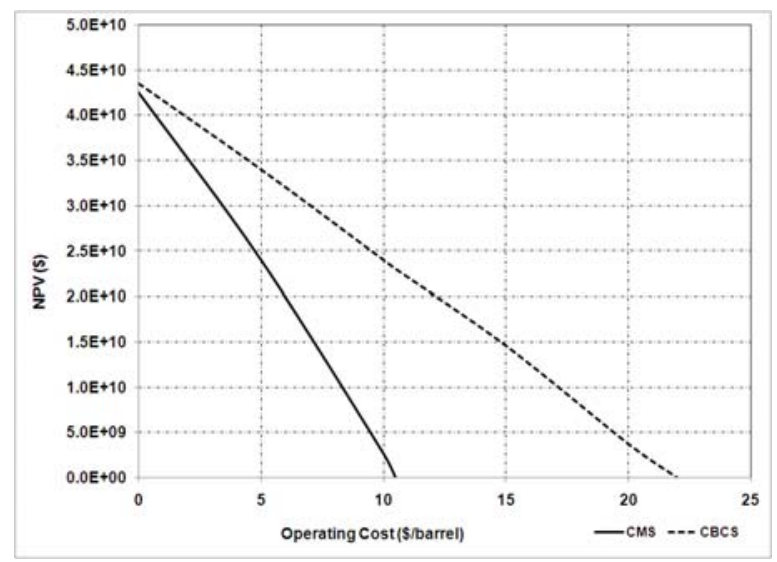

Fig. 5 NPV vs. Operating Costs (CMS option) [Source: Suglo et al., 2009]

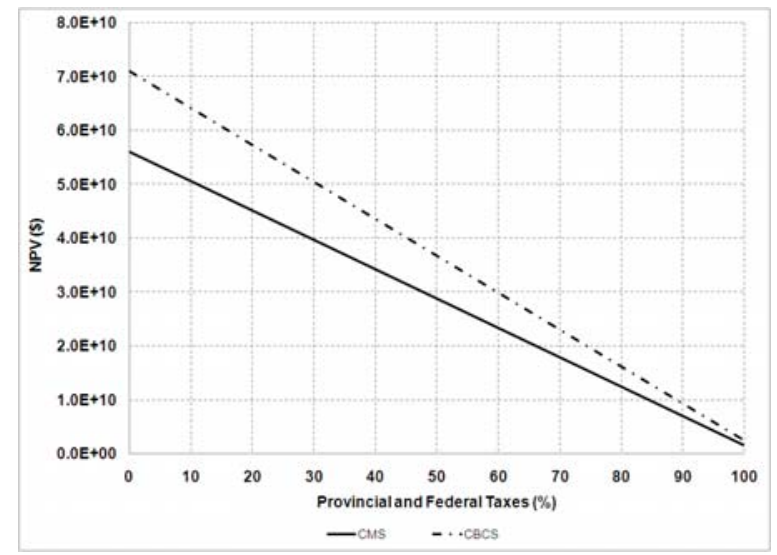

Fig. 6 NPV vs. Provincial and Federal Taxes for Mining Options [Source: Suglo et al., 2009]

option. Fig. 6 also shows that the difference between the NPV of the CMS and CycEx CBCS options increases inversely with the tax rate. At the $15^{\text {th }}$ percentile, when the tax rate is $5 \%$, there is $85 \%$ chance that the NPV of the CMS option and CycEx CBCS options will exceed \$45.15' $10^{9}$ and $\$ 57.14^{\prime} 10^{9}$ respectively. When the tax rate is increased to $60 \%$, there is $15 \%$ chance that the NPV of the CMS and CycEx CBCS options will be less than or equal to $\$ 20.08{ }^{\prime} 10^{9}$ and $\$ 25.53^{\prime} 10^{9}$ respectively.

\subsection{Sensitivity Analysis of Mining Options}

Using the autovary function in Toprank of @Risk software, the base values of the input parameters that directly affect the NPV of the mine (e.g. oil price, production capacity, discount rate, level of provincial and federal taxes) were varied between $\pm 25 \%$ to determine how sensitive the NPV is to changes in each of the input variables.

Figs. 7 and 8 are the tornado graphs of the results of what-if analysis of the various input parameters on the NPV of the CMS and CycEx CBCS options 
respectively. Fig. 7 shows that the discount rate, daily ore production, scheduled number of working days per year, oil price, exchange rate, production time and, provincial and federal taxes have significant effects on the NPV of the CMS option. For example, when the value of the discount rate is varied by $\pm 25 \%$, it has between $\pm 19.09 \%$ effect on the NPV of the CMS option while a similar change in the price of oil affects the NPV by only $\pm 6.96 \%$. The number of trucks has the least effect of $\pm 1.40 \%$ on the NPV of the CMS option.

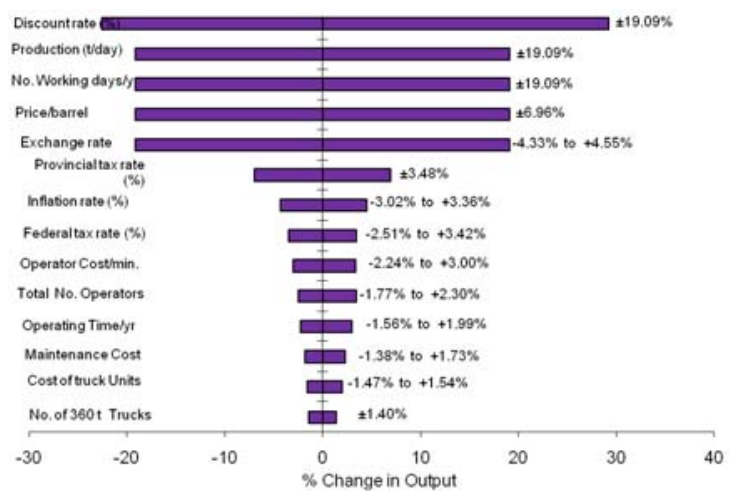

Fig. 7 Tornado Graph of NPV of CMS Option [Source: Suglo et al., 2009]

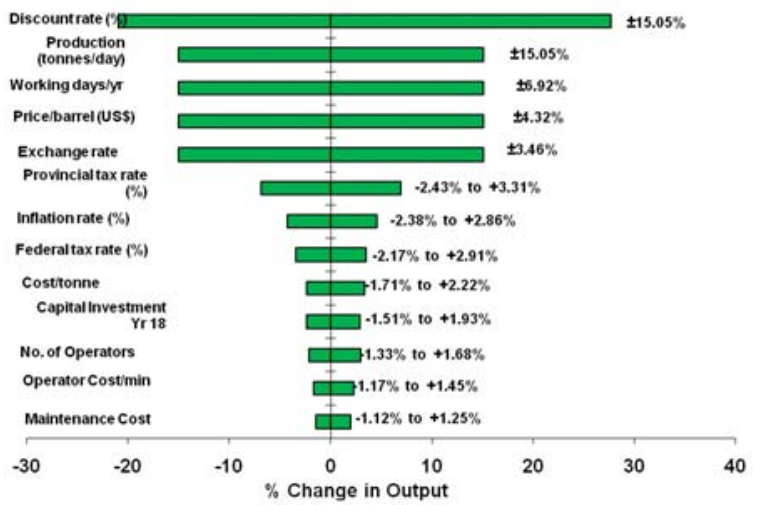

Fig. 8 Tornado Graph of NPV of CycEx CBCS Option [Source: Suglo et al., 2009]

In Fig. 8, the input variables that have the greatest effect on the NPV are the discount rate, the production capacity, number of scheduled working days, oil price, and the exchange rate between the Canadian and US dollars. Thus with the CycExc CBCS option, when the value of the discount rate is varied by $\pm 25 \%$, it affects the value of the NPV most by $\pm 15.05 \%$. The input parameters that have marginal effects on the NPV of the CycEx CBCS option are the maintenance cost, operator cost/min., and the level of capital investments made within the last three years of the mine life.

The results of sensitivity analysis of the NPV to marginal input variations show that when the dis- count rate is $17.06 \%$, there is a $22.52 \%$ decrease in the minimum value of the NPV for the CMS option. For the CycEx CBCS option, when the discount rate is $12.94 \%$, the value of the maximum NPV increases by $27.65 \%$. When the discount rate is $17.06 \%$, there is $20.99 \%$ decrease in the minimum value of the NPV for the CycEx CBCS option. While a $\pm 25 \%$ in the operator cost of shovels affects the NPV of the CMS option by between $2.24 \%$ and $+3.00 \%$, a similar change in the shovel operator costs only affects the NPV of the CycEx CBCS option by between $-1.17 \%$ and $+1.45 \%$. This means that even though the same number of shovels are employed in mining in both options, the operator costs of the CycEx CBCS option has a smaller negative impact on the NPV than that of the CMS option.

Figs. 9 and 10 are the spider graphs of the CMS and CycEx CBCS options respectively. Spider graphs show the percentage change in the base value of the input variables against the percentage change in the base value of the output variables. Both figures show that the daily ore production capacity, number of scheduled working days/year, production time, exchange rate, oil price per barrel

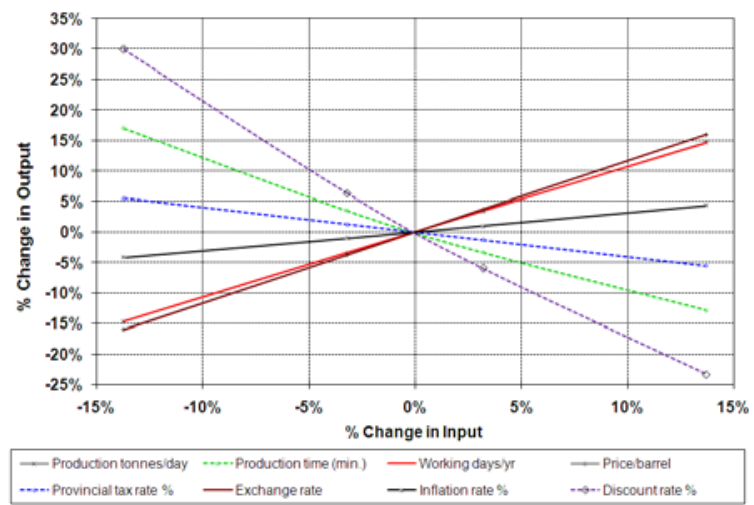

Fig. 9 Spider Graph for NPV of CMS Option [Source: Suglo et al., 2009]

have positive impact on the NPV. However, the discount rate, operating costs, inflation rate, federal and provincial tax rates negatively impact the NPV.

From the gradients of the plots in Figs. 9 and 10, the discount rate has a greater negative impact on the NPV than the provincial tax rate. The scheduled production time and capacity also have greater positive impact on the NPV than the exchange rate and price of oil. Thus the input variables that greatly affect the NPV in both mining options are the discount rate, operating costs, production rate, oil price per barrel, exchange rate, and the levels of federal and provincial taxes. 


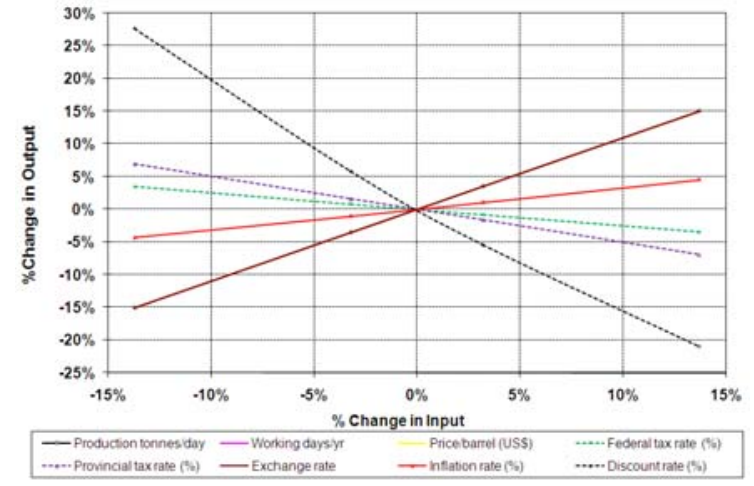

Fig. 10 Spider Graph for NPV of CycEx CBCS Option [Source: Suglo et al., 2009]

\section{Conclusions}

In this paper, economic, risk and sensitivity analyses were conducted on the current mining system and the cyclic excavator conveyor belt control system. The results of the economic analysis show that the NPV of the CMS option is $\$ 3.20^{\prime} 10^{10}$ while that for the CycEx CBCS option is \$4.06 ' $10^{10}$. The profitability indices for the CMS and CycEx CBCS options were 19.37 and 43.37 respectively. The internal rates of return of the CMS and CycEx CBCS options were calculated to be $29.02 \%$ and $33.37 \%$ respectively. Both the CMS and CycEx CBCS options have very short discounted payback periods of 0.27 years and 0.16 years respectively.

The results of risk characterisation of the two mining options show that there is $85 \%$ probability that the NPVs of the CMS and CycEx CBCS options will be greater than $\$ 2.69^{\prime} 10^{10}$ and $\$ 3.42^{\prime} 10^{10}$ respectively. The results of sensitivity analyses on the mining options show that the daily ore production capacity, number of scheduled working days/year, production time, exchange rate and oil price per barrel have the largest positive impact on the NPV. However, the discount rate, federal and provincial tax rates, and inflation rate negatively impact the mine's NPV.

Thus the input variables that significantly affect the NPV in both mining options are the discount rate, production rate, oil price per barrel, exchange rate, and the federal and provincial tax rates. In general, changes in input parameters such as discount rate, scheduled mine production capacity and time, price of oil per barrel and total operating costs had lower effects on the NPV of the CycEx CBCS option than the CMS option. The calculated economic parameters together with the results of the risk and sensitivity analyses show that the CycEx CBCS option is more economically viable than the CMS option.

\section{References}

Anon., (1979), "Belt Conveyors for Bulk Materials”, $2^{\text {nd }}$ ed., CBI Publishing Company, Inc., Boston, pp. 1 - 321.

Anon., (1993), Caterpillar Performance Handbook, $24^{\text {th }}$ ed., Caterpillar Inc., Peoria, USA, pp. 4-107 - 4-129.

Anon., (1997), @RISK: Risk Simulation and Analysis for Spreadsheets, (C) Palisade Corporation, Newfield, NY.

Anon., (2003a), "The Current Economy - Analysis of the Current State of the Economy", Government of Canada webpage, www.canadianeconomy.gc.ca, (date accessed: June 19, 2009).

Anon., (2003b), "Bank of Canada - Monetary Policy", Bank of Canada webpage, www.bankofcanada.ca/en/monetary.htm, (date accessed: June 17, 2009).

Bishop, T. S., (1968), "Trucks", in Ch. 9.2 of Surface Mining, $1^{\text {st }}$ ed., (E. P. Pfleider, sen. ed.), SME-AIME, New York, pp. 553 - 583.

Changirwa, R., Frimpong, S. and Szymanski, J., (2000), "AFS Recommended Option", Collaborative Research on an At Face Slurrying (AFS) Technology - NSERC-SyncrudeUniversity of Alberta, Progress Report \# NSERC/SCL/CRD00001 (January), pp. 1 - 61.

Coward, J., (2003), “Syncrude Canada Ltd”, Personal Communication.

Frizzell, E. M. and Martin, T. W., (1992), "In-Pit Crushing and Conveying”, in Ch. 13.5 of SME Mining Engineering Handbook, $2^{\text {nd }}$ ed., Vol. 2, (H. L. Hartman, sen. ed.), AIME, Baltimore, pp. 1343 - 1350.

Kutschera, S. A., (1994), "Selection Criteria for the Application of Continuous Mining and Transport Methods in Opencast”, Bulk Solids Handling, The Int. J. of Storing, Handling and Transporting, Vol. 14, No. 1, pp. 63 - 74.

Michaelson, S. D., (1979), "Open Pit Mining Past, Present and Future", in Ch. 1 of Open Pit Mine Planning and Design, Port City Press, Baltimore, pp. 3 - 16.

O’Neil, T., (1998), “Syncrude: Biggest Oil Sand Miner gets Biggest Hydraulic Shovel”, Mining Engineering, AIME-SME, Littleton, CO, pp. 33 - 39.

Suglo, R. S. and Szymanski, J., (1995), “Computer Simulation of Underground Room and Pillar Mining”, in Proc. of Underground Operators' Conference, Kalgoolie, November 13-14, 1995), pp. 1 - 4.

Suglo, R. S., (2004), “Geometrical Mine Design and Multi-Bench Material Flow Simulation for AFS Characterization”, PhD Dissertation, University of Alberta, Edmonton, Canada, pp. 1 181.

Suglo, R. S., Syzmanksi, J. and Planeta, S., (2009), "Simulation of At Face Slurrying Method and 
Continuous Miner Truck System in an Open Pit Mine”, Transport Journal, Vol. 1(3), pp. 2 8.

Sullivan, T. W., (1990), "New technology and economies of scale in shovel-truck sizing", Proc. of Second International Symposium on Mine Planning and Equipment Selection, (7-9 November), Calgary, Canada, (R. K. Singhal and M. Vavra, eds.), A. A. Balkema, Rotterdam, pp. 3 - 6.

\section{Author}

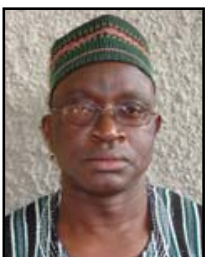

Raymond Suglo is a holder of $\mathrm{PhD}$ and MSc degrees in Mining Engineering (University of Alberta, Edmonton, Canada), a Postgraduate Diploma and Bachelor of Science (Honours) degrees in Mining Engineering (University of Science and Technology, Kumasi, Ghana). Raymond Suglo has over twenty years of professional experience in teaching, research and underground mining operations. He is presently an Associate Professor at the University of Mines and Technology, Tarkwa, Ghana. Before then he was a Senior Lecturer (October 1999 - September 2006), a Lecturer (May 1995 - September 1999) and an Assistant Lecturer (May 1989 - April 1995) at the same university. He also worked as a Production Engineer at Tarkwa Goldfields Limited from March 1983 to April 1989. His research areas are Mine Ventilation and Safety Engineering, Simulation of Mining Systems, Surface and Underground Mine Planning and Design, Small Scale Mining, Mining and Environmental Laws. From August 2006 to July 2008, he was the Head of the Mining Engineering Department. He is currently the Dean of Postgraduate Studies. He has to his credit 34 publications (thirteen refereed journal publications, twenty-one conference publications and twelve refereed forthcoming publications). He is a Member of the American Institute of Mining, Metallurgical and Petroleum Engineers, Inc. (SME) and the Canadian Institute of Mining, Metallurgy and Petroleum (CIM), Ghana Institution of Engineers (GhIE) 